\title{
Ergasilus triangularis sp. n. (COPEPODA: ERGASILIDAE) das BRÂNQUIAS de Laemolyta taeniata (KNER, 1859), (CHARA- CIFORMES: ANOSTOMIDAE) DA AMAZÔNIA BRASILEIRA.
}

\author{
José Celso O. MALTA'
}

\begin{abstract}
RESUMO - Ergasilus triangularis sp. nov, (Copepoda, Poecilostomatoida, Ergasilidae) é proposta. Os espécimens foram coletados dos filamentos branquiais de Laemolyta taeniata dos rios Jamari, Guaporé e Pacaás Novos do estado de Rondônia, Brasil. A nova espécie tem um espinho forte, pectinado e falciforme no artículo terminal do exopodito da primeira perna, indicando uma relação com outras sete espécies amazônicas de Ergasilus. Esta espécie difere das outras no tamanho dos espécimes, forma da antena e na ornamentaçäo das pernas.
\end{abstract}

Palavras chaves: Copepoda, Ergasilus, Amazônia, espécie-nova.

Ergasilus triangularis sp. n. (COPEPODA: ERGASILIDAE) from gill of Laemolyta taeniata (Kner, 1859), (CHARACIFORMES: ANOSTOMIDAE) from Brazilian Amazon.

ABSTRACT - Ergasilus triangularis sp. n. (Copepoda, Poecilostomatoida, Ergasilidae) is proposed. The specimens were collected from gill filaments of the freshwater fishes Laemolyta taeniata from the rivers Jamari, Guaporé and Pacaás Novos, Rondônia State, Brazil. The new species has a falciform, pectinate spine on the exopodite of the first leg, that indicates relationship to seven previously described Amazonian species of Ergasilus. This species differs from others in size, shape of the antenna and armature of the legs.

Key-words: Copepoda, Ergasilus, Amazon, new species.

\section{INTRODUÇÃO}

A grande maioria dos representantes da ordem Poecilostomatoida vive em associação com hospedeiros invertebrados, mas cerca de dez famílias utilizam peixes como hospedeiros. A menos modificada destas famílias, Bomolochidae, tende a ocupar microhabitats protegidos nos peixes, incluindo a cavidade nasal, boca, brânquias e órbitas. algumas espécies ocorrem na superfície externa do corpo. Formas menos modificadas como Chondracanthidae, ocupam esses mesmos microhabitats. Membros da família Philichthyidae tornaram-se parasitas internos e podem ser achados nos espaços subcutâneos, nos canais da linha lateral e nos ossos do crâneo de peixes teleósteos. Entre os parasitas de peixes está a família Ergasilidae, os quais junto com Vaigamidae representam a única grande invasão de água doce feita pelos Poecilostomatoida. Somente as fêmeas adultas destas espécies são parasitas, principalmente de peixes, mas também podem ocorrer em moluscos de água doce e salobra. Os estágios juvenis e os machos são de vida livre. Cerca de três quartos dos ergasilídeos conhecidos são encontrados em habitats de água doce, o restante em águas salobras e em habitats marinhos na costa (HUYS \& BOXSHALL, 1991).

1 Departamento de Biologia Aquática, Instituto Nacional de Pesquisas da Amazônia, Caixa Postal 478, Manaus, Amazonas, Brasil, CEP 69011-970 
$\mathrm{Na}$ regiäo Neotropical são conhecidas cerca de 37 espécies da família Ergasilidae, sendo que 22 são do gênero Ergasilus, três de Acusicola, uma de Amplexibranchius, quatro de Brasergasilus, três de Miracetyma, uma de Pindapixara, duas de Prehendorastrus e uma de Rhinergasilus. Destas 37 espécies, 24 foram descritas da região Amazônica (BOEGER \& THATCHER, 1990; WILSON, 1911; YAMAGUTI, 1969). Este trabalho descreve a $23^{a}$ espécie do gênero Ergasilus da região Neotropical e a $10^{\prime \prime}$ da região Amazônica.

\section{MATERIAL E MÉTODOS}

O material foi coletado no estado de Rondônia, região noroeste do Brasil, durante o período de 28 de novembro de 1983 a 25 de setembro 1985.

Os peixes foram identificados, pesados e medidos. As brânquias e vísceras foram removidas e fixadas em formol $10 \%$.

Os copépodos foram retirados dos filamentos branquiais utilizandose finos estiletes, microscópio estereoscópio, e transferidos para formol $5 \%$. Lâminas permanentes, com montagem total dos copépodos, foram preparadas usando o método de THATCHER, denominado "HYP". Cada indivíduo foi retirado da solução aquosa (formol $5 \%$ ) e mantidos em álcool $70 \%$. A seguir, colocados em solução corante, Eosina e Orange-G. Posteriormente colocados em fenol e em seguida em salicilato de metila. Finalmente, foram montados em bálsamo do Canadá entre lâmina e lamínula e colocados em estufa à $70^{\circ} \mathrm{C}$.

Os desenhos foram feitos com o auxílio de câmara clara. As medidas em micrômetros foram obtidas com uma ocular micrométrica. São dadas as amplitudes seguidas pela média entre parênteses.

Os peixes foram depositados na Coleção Ictiológica do Instituto Nacional de Pesquisas da Amazônia, em Manaus.

Os tipos foram depositados nas coleções do Instituto Nacional de Pesquisas da Amazônia (INPA-CR), Manaus, Amazonas e Museu de Zoologia da Universidade de São Paulo, (MZUSP), São Paulo.

\section{Ergasilus triangularis sp. $\mathrm{n}$}

(Figs. 1-11)

Holótipo: fêmea (INPA-CR 619), dos filamentos branquiais de Laemolyta taeniata do rio Jamari, lagoa Fortaleza, próximo a Ariquemes $\left(9^{\prime \prime} 56^{\prime} \mathrm{S}\right.$ e $\left.63^{\circ} 4^{\prime} \mathrm{W}\right)$, estado de Rondônia, Brasil 09-VI-1984, em lâmina. Parátipos 8 fêmeas (INPA-CR $620 \mathrm{a}-\mathrm{h}$ ) e 2 fêmeas (MZUSP 10444 a e b) em lâmina; 8 fêmeas (INPA-CR 621) e 2 fêmeas (MZUSP 10445) todas em formol $5 \%$ dos filamentos branquiais de Laemolyta taeniata, 6 coletadas em 2 peixes ( 3 examinados) na localidade tipo, 09-VI-1984; 13 fêmeas coletados em 3 peixes (4 examinados) no rio Guaporé, próximo a Pimenteiras ( $13^{\circ} 20^{\prime} \mathrm{S}$ e $\left.61^{\circ} 4^{\prime} \mathrm{W}\right)$, 30-XI-1984; 3 fêmeas coletadas em 1 peixe no rio Pacaás Novos próximo à Guajará-Mirim (10 $40^{\prime}$ 'S e $\left.65^{\prime \prime} 14^{\prime} \mathrm{W}\right)$, 
29-IX-1985; Todos coletados por J.C.O. Malta.

\section{Fêmea:}

Corpo (Fig.1) alongado, comprimento total 524-699 (607). Prossomo mais largo que o urossomo, largura do corpo 182-306(214). Cefalossomo (Fig. I) subtriangular, margem anterior reta, alarga-se até o terço final do cefalossomo, onde tem a maior largura, afina-se ligeiramente formando a segmentaçäo com o primeiro somito pedígero, margens laterais arredondadas. Em alguns exemplares é visível o olho bifurcado posteriormente de cor azul cobalto (cor 168 SMITHE, 1975) e pontos de pigmentação cobalto (cor 68 de SMITHE, 1975), espalhados aleatoriamente no prossomo e urussomo, com maiores concentrações no cefalom e no somito genital duplo. Metassomo (Fig. 1) com cinco somitos pedígeros (somitos do corpo 2, 3, 4, 5 e 6), todos mais largos que compridos, claramente separados e decrescendo suas larguras gradualmente na direçäo terminal.

Urossomo (Figs. 1, 2 e 3) cerca de um quarto do comprimento do prossomo e somito $6 \mathrm{com}$ as pernas natatórias rudimentares. Somito genital duplo (Figs. 1 e 2) suborbicular mais largo que comprido, comprimento 37 57(48), largura 52-72(65), margens laterais arredondadas. Somitos abdominais (Figs. 1 e 2), somitos abdominais 1 e 2 sub-retangulares; somito abdominal 3 (anal) sub-retangular com a margem anterior reta e a posterior com as porções laterais projetando-se quase o dobro do comprimento da região central do somito. Ramos caudais
(Figs. 1, 2 e 3) sub-retangulares, ambos equipados com uma seta longa e uma curta, duas setas reduzidas e com uma fileira de espinhos ventralmente, próximos ás áreas de inserçäo das setas reduzidas laterais. Setas caudais medindo 117-225(188).

Antênula (Fig. 4) comprimento 102-155(120) e largura 20-35(23), cilíndrica, reduzida, com seis segmentos, carregando 24 setas simples e com fórmula setal: $1-10-4-3-1-5$. Tipologia, comprimentos relativos e ornamentações diretamente comparáveis com os representantes da subfamília. Antena (Fig. 5) com três segmentos. Segmento I subtriangular, o menor e o mais robusto, comprimento 50-87(53), largura 37-50(45); segmento 2 subretangular, o mais longo, margens interna e externa retas e paralelas; comprimento 150-175(160), largura 2255(33); segmento 3 o mais fino, comprimento $120-147$ (127) e largura 22-37(28), com um espinho na margem proximal interna, região anterior mais larga que a posterior; processo distal é uma forte garra curva, comprimento 70-87(78) e largura 12-17(15). A relação entre os segmentos incluindo a garra é $1,0: 3,1: 2,3: 1,5$.

Peças bucais (Fig. 6): mandíbula longa, com uma base robusta, subretangular, no terço distal da regiäo basal sua largura reduz à metade e na margem posterior, origina-se o palpo mandibular, falciforme e com uma série de minúsculos dentes na margem posterior, o processo basal continua estreito, há uma segmentação onde a partir daí inicia-se uma lâmina falciforme, 
bífida na extremidade distal e com minúsculos dentes nas margens anteriores e posteriores. Maxílula ausente. Maxila, bi-segmentada, processo proximal extremamente robusto, largo, sem ornamentações e fortemente preso ao cefalossomo, processo distal alongado, robusto, base mais larga, terminalmente falciforme com setas espiniformes circundando as margens anteriores. Maxilípedes ausentes.

Pernas (Figs. 7 - 10) providas de setas plumosas. Perna I (Fig. 7), endopodito com dois segmentos e exopodito com três. Segmento 1 do endopodito, robusto, sub-retangular e com uma seta na margem interna; segmento 2 sub-retangular, robusto, quase com o dobro do tamanho do anterior, com cinco setas e dois fortes espinhos. Segmento 1 do exopodito robusto, sub-retangular, o maior, com o dobro do tamanho dos demais e com um espinho; segmento 2 com uma seta; segmento 3 com quatro setas, uma seta forte, pectinada, falciforme e dois espinhos.

Perna II (Fig. 8) semelhante à perna III com ambos os ramos de três segmentos. Os dois primeiros segmentos do endopodito, com uma fileira de espinhos na margem externa. Segmento 1 robusto, o maior e com uma seta; segmento 2 com duas setas; segmento 3 com quatro setas e um espinho. Segmento 1 do exopodito o maior, cerca de duas vezes maior que os demais e com um espinho; segmento 2 sem omamentações; segmento 3 com cinco setas e um espinho.
Perna IV (Fig. 9) com ambos os ramos de dois segmentos. Segmento 1 do endopodito sub-retangular e com uma seta; segmento 2 sub-retangular, com cinco setas e um espinho. Segmento 1 do exopodito com o dobro do tamanho do 2 e com um espinho; segmento 2 com quatro setas e um espinho.

Perna V (Fig. 10) vestigial, consistindo de duas setas simples que se originam em uma papila.

Saco ovígero (Fig. 11) com duas séries de ovos que variam, numericamente, de doze a 16.

Macho: Desconhecido.

Etimologia: O nome específico deriva do latim triangularis, em alusäo ao formato triangular do cefalossomo.

\section{DISCUSSÃO}

Ergasilus triangularis sp. n. tem uma seta forte, pectinada, falciforme, no segmento terminal do exopodito da primeira perna, indicando afinidades com E. bryconis Thatcher, 1981; E. jaraquensis Thatcher \& Robertson, 1982; E. hydrolycus Thatcher, Boeger \& Robertson, 1984; E. callophysus Thatcher \& Boeger, 1984; E. holobryconis Malta \& Varella, 1986; E. urupaensis Malta, 1993, E. turucuyus Malta, 1993 (MALTA, 1992; THATCHER, 1991; VARELLA, 1992).

O comprimento total de $E$. triangularis variou de 524 a 699 , situando-se numa faixa muito semelhante à de $E$. leporinidis Thatcher, $1981,530 \mathrm{a}$ 710 e E. colomesus Thatcher \& Boeger, 1983,540 a 700 . 


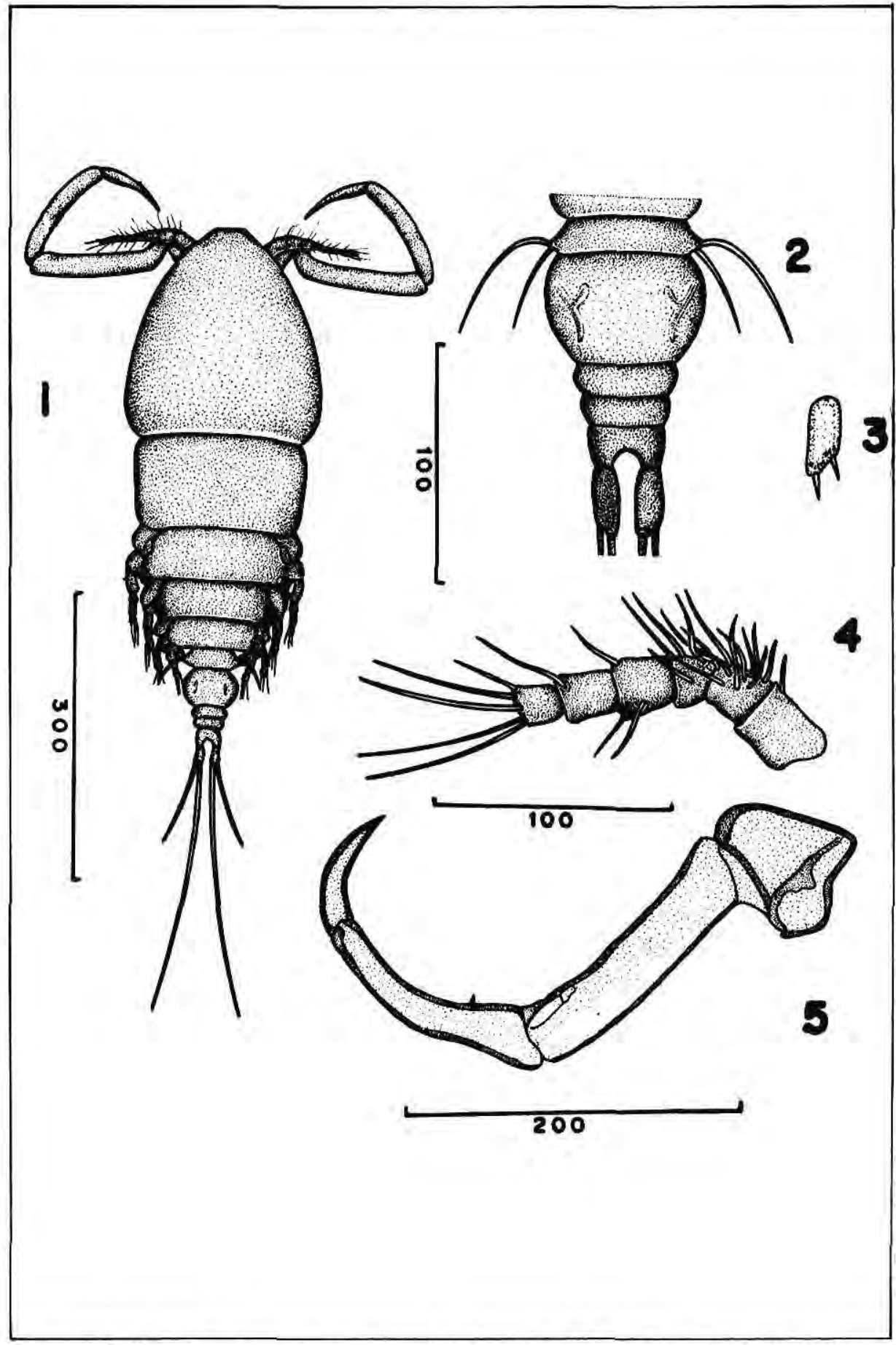

Figura 1-5. Ergasilus triangularis sp. n. (fềmea). 1- vista dorsal. 2 - somito genital duplo, abdômen e ramos caudais. 3 - ramo caudal (vista ventral), 4 - antênula. 5 - antena (medidas em micrômetros). 


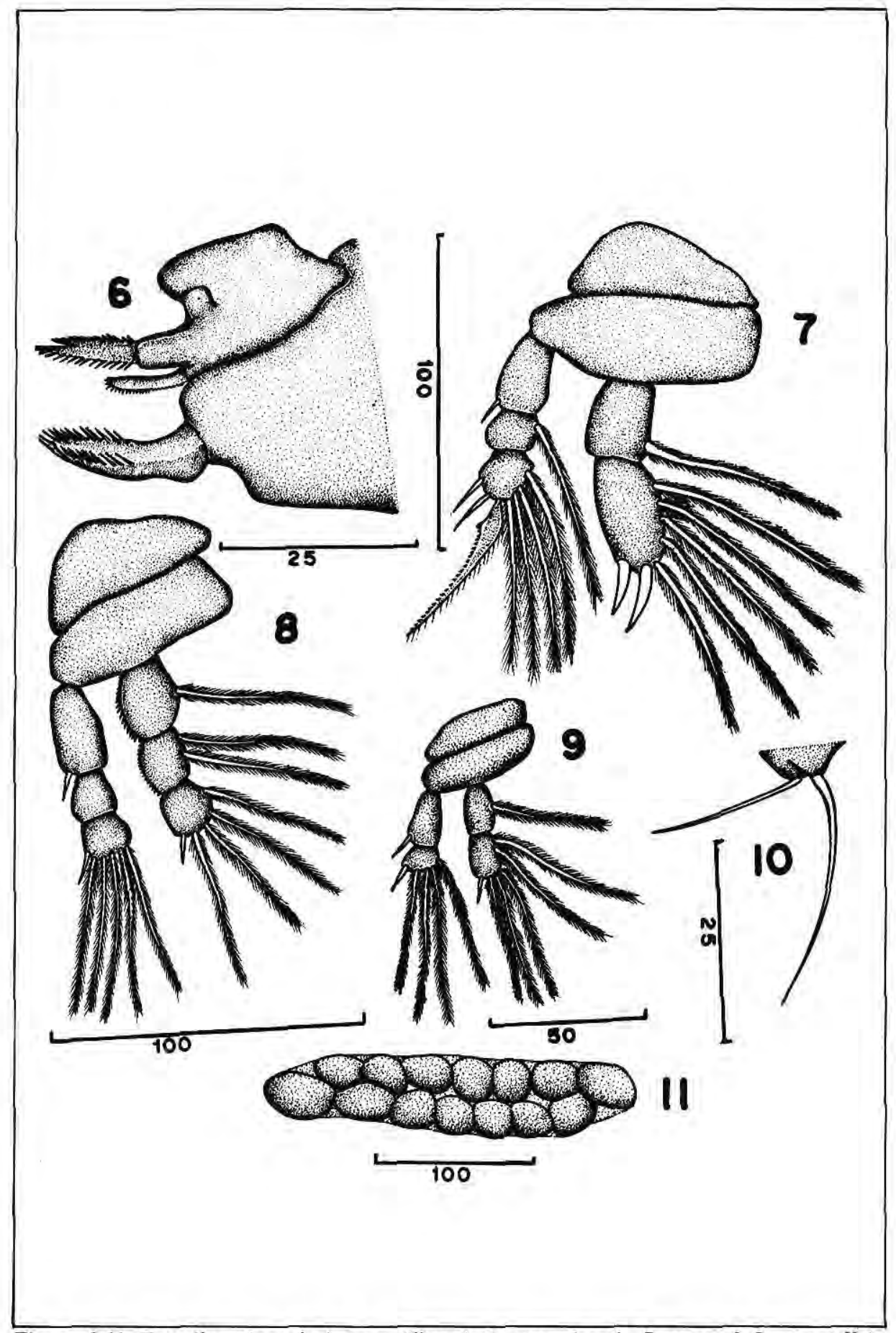

Figura 6-11. Ergasilus triangularis sp. n. (fềmea). 6-peças bucais. 7 - perna I. 8 - perna II (= perna III). 9 - perna IV. 10 - perna V. - 11 - saco de ovos. (medidas em micrômetros). 
Comparando-se o comprimento do cefalotórax de $E$. triangularis com o de outras espécies de Ergasilus verifica-se que, nesta espécie, corresponde a $48,0 \%$ do comprimento total, mesma proporção encontrada por THATCHER (1984) para E. versicolor e MALTA (1993) para E. urupaensis.

E. triangularis tem o somito genital duplo suborbicular como em $E$. pitalicus Thatcher, 1984. Sua mandíbula é bífida e com dentículos em ambas as margens, como em $E$. turucuyus. Não foi observado a maxílula como em $E$. jaraquensis. Apresenta ligeira projeção na região das antenas, como em $E$. bryconis, E. pitalicus, E. urupaensis e $E$. turucuyus. A ornamentação da antena, com um espinho na região proximal do terceiro segmento é semelhante à $E$. urupaensis.

A combinação destes caracteres, aliados a ausência de ornamentação no segundo segmento do exopodito da segunda e terceira pernas, formato alongado e delgado do segundo segmento da antena säo características exclusivas de $E$. triangularis.

Os índices que estimam o tamanho da populaçäo de $E$. triangularis são: prevalência $50,0 \%$; intensidade entre 1 - 20 copépodos por peixe: intensidade média 8,0 e abundância 4,0 .

\section{Bibliografia Citada}

BOEGER, W. A;; THATCHER, V. E. 1990. Prehendorastrus n. g. (POECILOSTOMATOIDA: ERGASILIDAE) with descriptions of two new species from the gill rakers of Hypophtalmus spp. (TELEOSTEI: SILURIFORMES) from the Brazilian Amazon. Sys. Parasit., 17: 133-141.

HUYS, R.; BOXSHALL, G. A. 1991، Copepod Evolution. London: The Ray Society, $468 \mathrm{p}$.

MALTA, J. C. O. 1992. Copépodos (CRUSTACEA: ERGASILIDAE) das brânquias de peixes do sudoeste da Amazônia Brasileira (Rondônia). Tese de Doutorado. UNESP - Rio Claro, Säo Paulo. $171 \mathrm{p}$.

-... - 1993. Ergasilus urupaensis sp. n. (COPEPODA: ERGASILIDAE) das brânquias de Prochilodus nigricans AGASSIZ, 1829 (CHARACIFORMES: PROCHILODONTIDAE) da Amazônia Brasileira. Acta Amazônica (no prelo).

SMITHE, F. B. 1975. Naturalist's Color Guide and Supplement. New York: Amer:Mus. Nat. Hist, Colors I $-86+229$ p.

THATCHER, V. E. 1984. Ergasilus pitalicus, new species (COPEPODA: POECILOSTOMATOIDA: ERGASILIDAE), a gill parasite of a cichlid fish from the Pacific coast of Colombia. J. Crust. Biol. 4(3):495-501.

-... 1991, Amazon Fish Parasites. Amazoniana, 11(3/4): $263-572$.

VARELLA, A. M. B. 1992. Copépodos (CRUSTACEA) parasinas das fossas nasais de peixes, coletados na regiāo de Rondônia, Brasil. Tese de doutorado. UNESP, Rio Claro, São Paulo, 105p.

WILSON, C. B. 1911. North American parasitic copepods belonging to the family Ergasilidae. Proc. U. S. Nat. Mus., 39:263-400.

YAMAGUTI, S. 1969. Parasites Copepoda and Branchiura of fishes. New York: John Wiley, 1104p. 